\title{
Tumor desmoplásico de pequenas células redondas abdominal da infância: relato de caso
}

\section{Abdominal desmoplastic small round cell tumor of childhood: case report}

Ulysses dos Santos Torres'; Mariana Cezar de Andrade Ribeiro²; Antonio Soares Souzaㄹ; Leila Neves Bastos Borim ${ }^{4}$

unitermos

Tumor desmoplásico

Sarcoma de partes moles

Infância

\section{resumo}

O tumor desmoplásico de pequenas células redondas (TDPCR) é uma neoplasia rara e altamente agressiva, que afeta predominantemente jovens do sexo masculino. Relata-se um caso de TDPCR em um paciente do sexo masculino, de 11 anos, com acometimento intra-abdominal marcado por volumosa massa retroperitoneal em hipocôndrio esquerdo. O estudo histológico da massa revelou presença de blocos de pequenas células tumorais redondas e azuis, envoltas por estroma desmoplásico; a análise imuno-histoquímica evidenciou positividade para desmina, WT-1 e citoceratinas. Após o diagnóstico, o paciente foi submetido a tratamento quimiorradioterápico, tendo evoluído a óbito durante o $24^{\circ}$ mês de acompanhamento.

\section{abstract}

Desmoplastic small round cell tumor (DSRCT) is a rare and highly aggressive neoplasm, which predominantly affects young males. We report a case of DSRCT affecting an 11 -year-old male patient, with intra-abdominal involvement characterized by a large retroperitoneal mass in left hypochondrium. Histological examination of the mass showed the presence of clusters of small blue round tumor cells surrounded by a dense desmoplastic stroma. Immunohistochemical analysis disclosed a positive reaction to desmin, WT-1 and cytokeratins. After diagnosis, the patient underwent chemo radiotherapy treatment, but died at the 24th month of follow-up. key words

Desmoplastic tumor

Soft tissue sarcoma

Childhood

1. Graduando em Medicina pela Faculdade de Medicina de São José do Rio Preto (FAMERP).

2. Médica patologista do Serviço de Anatomia Patológica do Hospital de Base de São José do Rio Preto.

3. Doutor em Radiologia pela Universidade de São Paulo (USP); docente do Departamento de Radiologia e Diagnóstico por Imagem da FAMERP.

4. Doutora em Pediatria pela USP; docente do Departamento de Pediatria da FAMERP. 


\section{Introdução}

O tumor desmoplásico de pequenas células redondas (TDPCR) é uma neoplasia rara e altamente agressiva, pertencente ao grupo dos sarcomas de partes moles ${ }^{(1)}$, de aspectos clínicos, histológicos e imuno-histoquímicos característicos $^{(11)}$. O primeiro estudo anatomopatológico dessa neoplasia ocorreu em 1989(12), e em 1991 houve seu reconhecimento como entidade clínica e patológica distinta $^{(11)}$.

O TDPCR acomete predominantemente crianças e adolescentes do sexo masculino (4:1), com média de idade de 21 anos ${ }^{(17,20,21)}$. A localização é intra-abdominal na maioria dos casos, sem origem visceral claramente identificada, com acometimento peritoneal difuso e apresentação clínica com desconforto, distensão e volumosas massas abdominais $(11,17,20,22)$. Outras localizações descritas incluem fígado, ovários, pleura e tunica vaginalis $(4,7,14,25)$. Os sítios de metástases mais frequentes são fígado, tecido linfoide e peritônio ${ }^{(14,17,20)}$. A taxa de sobrevida relatada em 5 anos é de $15 \%{ }^{(19)}$, com média de 17 meses $^{(11)}$.

A realização de estudo imuno-histoquímico evidencia expressão de marcadores embrionários epiteliais, mesenquimais e neurais ${ }^{(13)}$. A associação desses achados com estudos histológicos favorecem o diagnóstico de TDPCR. A translocação recíproca $\mathrm{t}(11 ; 22)(\mathrm{p} 13 ; \mathrm{q} 12)$ também pode ser encontrada ${ }^{(3,9)}$.

Na literatura mundial há menos de 200 casos relatados de $\operatorname{TDPCR}^{(5)}$, tendo sido encontrados nesta revisão apenas quatro relatos prévios na literatura nacional. A seguir são apresentados aspectos clínicos, radiológicos, histológicos e imuno-histoquímicos de um caso de TDPCR.

\section{Relato do caso}

Relata-se o caso de um paciente do sexo masculino, 11 anos, que se apresentou clinicamente com queixa de dor abdominal em hipocôndrio esquerdo com irradiação para a região dorsal. Relatava hiporexia pelos seis meses anteriores, aparecimento de abaulamento em topografia de hipocôndrio esquerdo mais pronunciadamente no mês anterior, emagrecimento de $5 \mathrm{~kg}$ desde o início do quadro (cerca de $15 \%$ da massa corporal total) e sensação de plenitude pós-prandial. Negava febre, náuseas e vômitos e não possuía antecedentes pessoais dignos de nota ou história familiar de neoplasias. Ao exame físico apresentava massa palpável e dolorosa em hipocôndrio esquerdo, não móvel, que se estendia cerca de $10 \mathrm{~cm}$ do rebordo costal esquerdo.
Realizou-se tomografia computadorizada (TC) de abdome, que revelou imagem heterogênea, de contornos definidos, projetada em topografia de hipocôndrio esquerdo, rechaçando o baço lateralmente, e que sofria discreto realce após a injeção endovenosa do meio de contraste. A massa media aproximadamente $13 \times 10 \mathrm{~cm}$ em seus maiores eixos, com sinais de deslocamento e envolvimento do rim esquerdo (Figura 1). A ressonância magnética (RM) de abdome superior confirmou os achados da TC (Figura 2).

Efetuou-se biópsia da massa abdominal, guiada por TC, com estudo anatomopatológico e imuno-histoquímico. $\mathrm{O}$ exame anatomopatológico revelava blocos sólidos e bemdefinidos de pequenas células tumorais redondas e azuis, com certa coesão entre si, envoltas por estroma desmoplásico denso (Figura 3), sendo que a proporção entre a quantidade de células tumorais e o estroma adjacente variava de acordo com o campo analisado. As células tumorais apresentavam bordas mal definidas, citoplasma escasso e núcleos hipercromáticos, estes últimos com o formato variando de redondo a oval, e nucléolos pouco evidentes. Figuras ocasionais de mitoses também foram observadas. Já o estudo imuno-histoquímico evidenciou expressão de WT-1 e desmina em padrão dot-like (Figura 4) pelas células neoplásicas, além de citoceratinas (Tabela). Os achados anatomoclínicos associados ao estudo imuno-histoquímico confirmaram o diagnóstico.

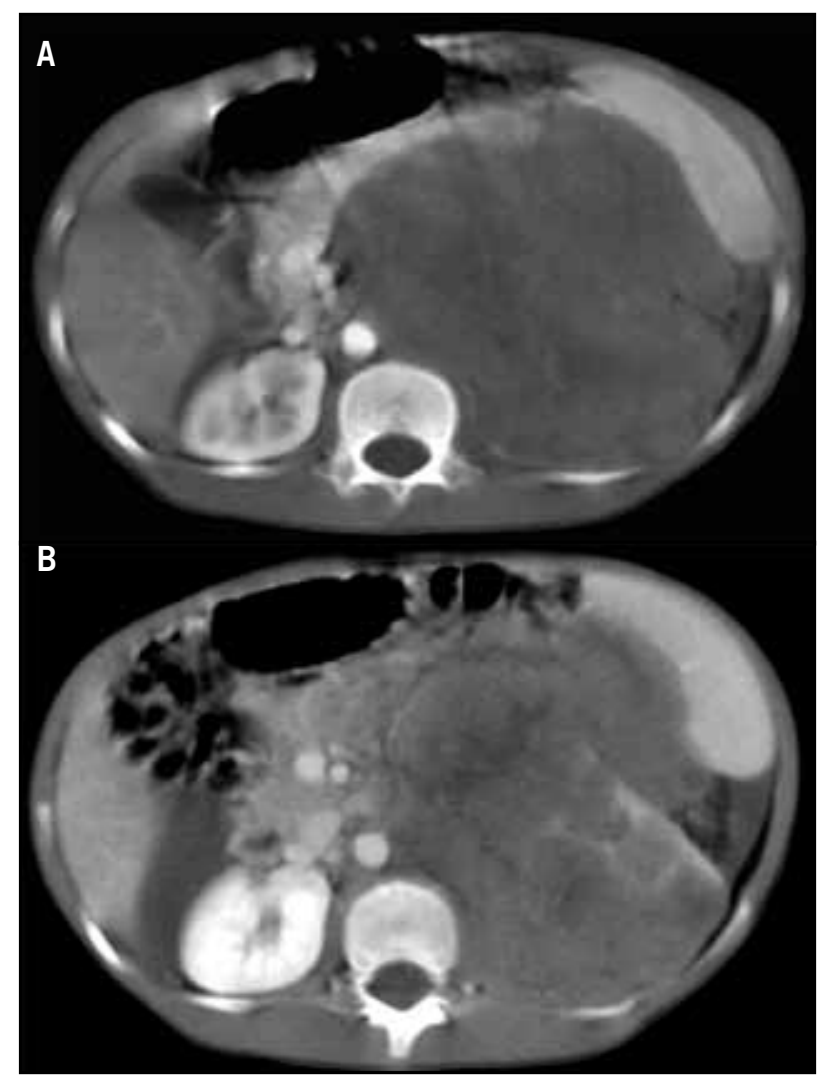

Figura 1 - A: tomografia computadorizada do abdome revela volumosa massa retroperitoneal determinando deslocamento anterior do pâncreas e do baço; $B$ : deslocamento e envolvimento do rim esquerdo determinado pela massa retroperitoneal 


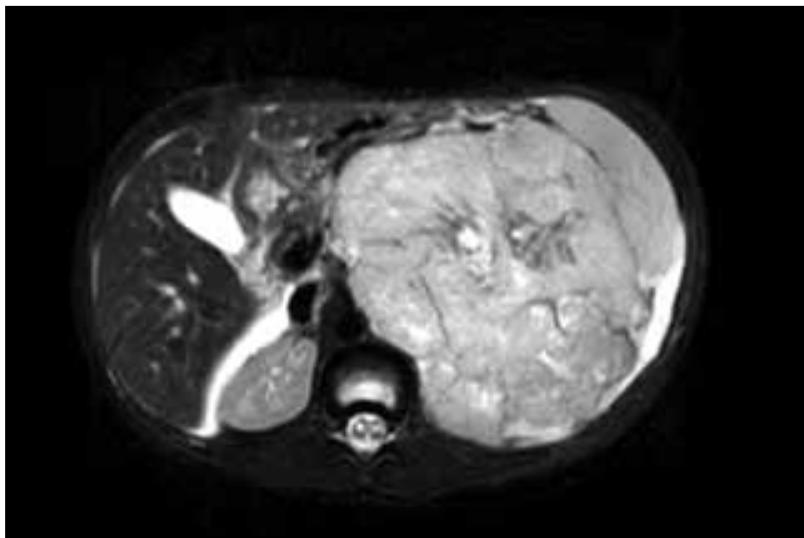

Figura 2 - Ressonância magnética de abdome evidenciando presença de grande massa retroperitoneal à esquerda, com deslocamento anterior do baço

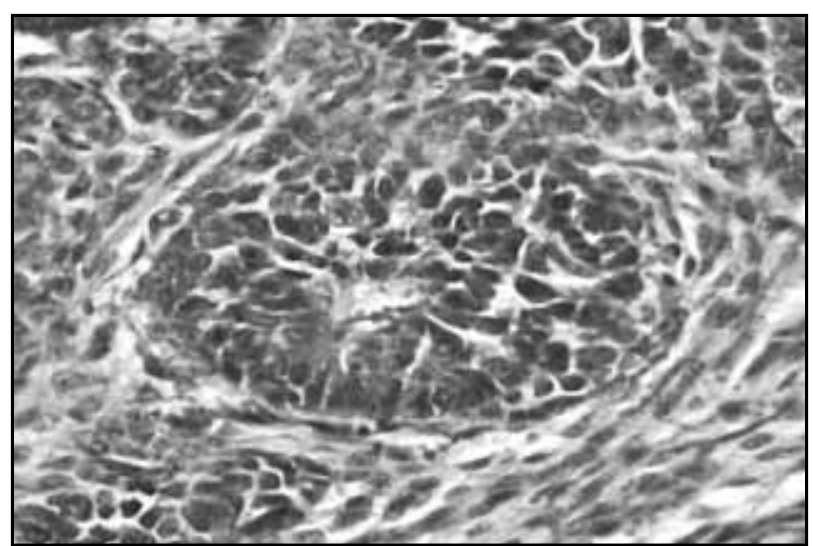

Figura 3 - Coloração por hematoxilina e eosina, aumento de 200 vezes. Observa-se ninho de pequenas células tumorais redondas e coesas, envoltas por denso estroma fibroso

Ao longo dos 18 meses seguintes o paciente foi submetido a tratamento com ciclos de radioterapia e quimioterapia, esta última em esquema de etoposídeo e ifosfamida, com intercalação de adriamicina, ciclofosfamida e vincristina. No quinto mês do tratamento, a RM apontava importante

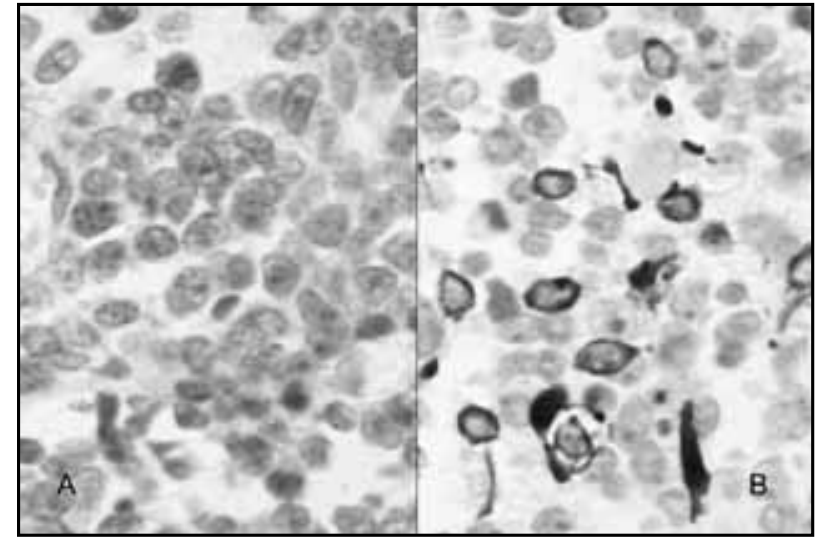

Figura 4 - Aumento de 400 vezes. A: imuno-histoquímica mostrando reatividade para WT-1; B: imuno-histoquímica mostrando reatividade para desmina, em padrão dot-like

redução da massa, cujas dimensões passaram a ser de $2,6 \times 2,3 \times 2 \mathrm{~cm}$, situando-se junto ao polo superior do rim esquerdo e borda medial do baço. Uma nova RM de controle durante o $15^{\circ}$ mês de tratamento mostrava que a redução volumétrica da massa se mantinha. Em nenhum exame houve evidências de lesões pélvicas.

Durante o $20^{\circ}$ mês de seguimento foi efetuada outra RM, que apontou presença de múltiplas massas em topografia de loja renal esquerda, com aumento das dimensões em relação ao exame anterior. Realizou-se uma laparotomia exploratória, a qual mostrou tumor irressecável, visualizado desde a borda superior do rim esquerdo até a crista ilíaca, infiltrativo em rim esquerdo, músculo psoas, peritônio posterior e cólon descendente. Efetuou-se ressecção de uma amostra tumoral em retroperitônio $(3 \times 3 \mathrm{~cm})$ e encaminhamento para análise anatomopatológica. Novos estudos histológicos e imunohistoquímicos foram realizados, ratificando o diagnóstico prévio de TDPCR intra-abdominal da infância.

A partir de então, o paciente foi submetido a um novo protocolo quimioterápico, com ifosfamida, etoposídeo e
Tabela

\begin{tabular}{|c|c|c|c|c|}
\hline Anticorpo & Clone & Empresa & Diluição & Resultado \\
\hline $\begin{array}{l}\text { CD45RB - antígeno } \\
\text { leucocitário comum } \\
\text { (pan-hematopoiético) }\end{array}$ & PD7/26/16 \& 2B11 & Dako & $1: 500$ & Negativo \\
\hline $\begin{array}{c}\text { Citoceratinas } \\
(40,48,50 \text { e } 50,6 \mathrm{kDa})\end{array}$ & AE1/AE3 & Dako & $1: 900$ & Positivo \\
\hline Cromogranina A & DAK-A3 & Dako & $1: 3200$ & Negativo \\
\hline Desmina & D33 & Dako & 1:3200 & Positivo (padrão dot) \\
\hline Proteína S-100 & Policlonal & Dako & $1: 5000$ & Negativo \\
\hline Sinaptofisina & SP11 & NeoMarkers & $1: 1350$ & Negativo \\
\hline WT-1 & C19 & Dako & $1: 400$ & Positivo \\
\hline $\begin{array}{l}\text { CD99 - proteína de } \\
\text { adesão MIC (p30/32) }\end{array}$ & 013 & Dako & $1: 800$ & Focalmente positivo \\
\hline
\end{tabular}


carboplatina. A última TC de abdome efetuada no $23^{\circ}$ mês de seguimento apontava massa heterogênea em loja renal esquerda, com dimensões de $6,6 \times 5,5 \mathrm{~cm}$. Ao final do $23^{\circ}$ mês de seguimento o paciente foi internado com quadro de febre e queda do estado geral. A investigação diagnóstica revelou formação de múltiplos abscessos hepáticos. Não houve resposta aos esquemas terapêuticos adotados. Houve piora progressiva do estado geral e o paciente evoluiu com sepse e choque séptico, indo a óbito no início do $24^{\circ}$ mês de seguimento.

\section{Discussão}

O termo tumor de pequenas células redondas refere-se a um grupo de neoplasias malignas altamente agressivas que se constituem histopatologicamente por pequenas células indiferenciadas, de núcleos hipercromáticos redondos ou ovais, com nucléolos pouco evidentes e citoplasma bastante escasso ${ }^{(17)}$. Incluem-se nesse grupo neoplasias como sarcoma de Ewing, tumor neuroectodérmico primitivo periférico (neuroepitelioma periférico), neuroblastoma periférico, rabdomiossarcoma, linfomas, leucemias, osteossarcoma de pequenas células e TDPCR, todos incidentes mais comumente na faixa pediátrica. Outras neoplasias do grupo, mais incidentes em adultos, são carcinoma de pequenas células, melanoma de pequenas células, entre outras( ${ }^{(8)}$.

O TDPCR é encontrado predominantemente em adolescentes e adultos jovens. Relata-se variação da idade dos pacientes ao diagnóstico entre 3 e 48 anos, com média de idade de $21 \operatorname{anos}^{(20)}$. As manifestações clínicas do TDPCR intra-abdominal são usualmente inespecíficas e envolvem mais frequentemente sintomas vagos pélvicos ou abdominais e massas palpáveis.

A histopatogênese do TDPCR permanece ainda indefinida. Devido ao fato de a maioria desses tumores crescerem na cavidade peritoneal, e por muitas vezes não apresentarem um sítio visceral primário de origem, acredita-se que essa neoplasia possua origens mesoteliais ou mesenquimais ${ }^{(11)}$. Como o TDPCR pertence a um grupo de características histopatológicas muito similares, pode haver certa dificuldade diagnóstica na diferenciação com as outras neoplasias que compõem o grupo. Apesar disso, o diagnóstico pode ser estabelecido por meio da correlação entre aspectos clínicos, histológicos e imuno-histoquímicos do tumor. Diferentemente de outros tumores de pequenas células redondas, ao estudo imuno-histoquímico o TDPCR revela um padrão de diferenciação polifenotípica, com expressão de marcadores epiteliais e mesenquimais, além de usualmente mostrar um padrão dot-like de desmina e vimentina ${ }^{(11,12,16)}$.

Em uma série de 19 casos de TDPCR, revelou-se que $88 \%$ eram imunorreagentes para citoceratinas AE1/AE3, 84\% para enolase neurônio-específica (NSE) e $81 \%$ para desmina ${ }^{(11)}$. Os resultados encontrados no presente caso estão de acordo com os dados encontrados na literatura, revelando positividade para citoceratinas AE1/AE3, WT-1 e desmina (esta última com padrão dot-like, caracterizado por reatividade, mostrando padrão paranuclear globular, que à microscopia eletrônica corresponde a grupamentos de filamentos intermediários em posição paranuclear).

Outros marcadores de diferenciação neuroendócrina foram pesquisados, a exemplo da cromogranina A, sinaptofisina e proteína S-100, que se mostraram negativos. A pesquisa do antígeno leucocitário comum, específico de linfomas, também se revelou negativa. O estudo de CD99, marcador da proteína de superfície MIC2 (transcrito do gene $\mathrm{MIC2}$, localizado na região pseudoautossômica no final do braço curto dos cromossomos $X$ e $Y$ ), mostrou-se focalmente positivo. O CD99 é um marcador relativamente não específico do neuroepitelioma periférico, assumindo, quando positivo, um padrão difuso. Na maioria das vezes é negativo nos TDPCR, podendo às vezes revelar um padrão focalmente positivo, mais comumente citoplasmático (como encontrado no presente caso). No neuroepitelioma periférico, o padrão é tradicionalmente membranoso ${ }^{(10,16,18)}$.

O estabelecimento de uma translocação recíproca específica $\mathrm{t}(11 ; 22)(\mathrm{p} 13 ; 12)$ como ferramenta diagnóstica no TDPCR baseia-se em resultados publicados por Sawyer et al.(24). A translocação envolve o gene EWS (22q24) e o gene WT-1 (11p13), produzindo o transcrito EWS/WT-1 e a correlata proteína WT-1, passível de detecção por estudo imunohistoquímico. A detecção imuno-histoquímica de WT-1 no TDPCR é preditora da translocação, além de demonstrar que a proteína quimérica é expressa em quantidade significativa pelas células tumorais ${ }^{(2,6)}$. A partir da análise de uma série de 32 casos, Lae et al. relataram positividade para o anticorpo WT-1 em 29 deles $^{(18)}$. No presente caso não foi realizado o estudo da translocação, mas a pesquisa de WT-1 por imunohistoquímica mostrou-se positiva, corroborando o diagnóstico.

Devido à elevada agressividade do TDPCR, sua completa ressecção não é passível de realização na maior parte das vezes, por causa do acometimento peritoneal múltiplo e difuso. Além disso, a falta de padronizações e critérios de estadiamento e o número reduzido de pacientes com a doença tornam difícil o estabelecimento de evidências para otimização do tratamento. A ressecção cirúrgica é recomendada somente nos casos de doença não metastática, em combinação com quimiorradioterapia. O uso não associado dessas opções terapêuticas pode ser fator negativo de interferência na melhora clínica e na sobrevida desses pacientes. No caso de doença metastática, é importante $o$ controle sintomático, independentemente do impacto na sobrevida, o qual se acredita ser praticamente nulo ${ }^{(14,15,23)}$.

O prognóstico do TDPCR é bastante desfavorável, e o tempo relatado de sobrevida média é inferior a 2 anos ${ }^{(11,16)}$. Em estudo de 1993, Ordóñez et al. relataram mortalidade de 16 pacientes (em um grupo de 22) entre oito e 50 meses 
após o estabelecimento da terapia inicial ${ }^{(21)}$. O paciente do caso em questão apresentou sobrevida de 24 meses, o que se encontra dentro do relatado na literatura.

Finalmente, é fundamental que desde o processo diagnóstico, passando pela definição terapêutica, a abordagem do paciente com TDPCR seja efetuada por uma equipe multidisciplinar, e que o acompanhamento seja realizado em um centro especializado, objetivando-se não somente a melhora nas taxas de sobrevida, mas também o alcance de um impacto benéfico sobre a qualidade de vida.

\section{Referências}

1. ANTONESCU, C. R.; GERALD, W. World Health Organization Classification of Tumours. Pathology and genetics of tumours of soft tissue and bone. Lyon: IARC Press, 2002.

2. BARNOUD, R. et al. Immunohistochemical expression of WT1 by desmoplastic small round cell tumor: a comparative study with other small round cell tumors. Am J Surg Pathol, v. 24, n. 6, p. 830-6, 2000.

3. BENJAMIN, L. E. et al. Fusion of the EWS1 and WT1 genes as a result of the $t(11 ; 22)(p 13 ; q 12)$ translocation in desmoplastic small round cell tumors. Med Pediatr Oncol, v. 27, n. 5, p. 434-9, 1996.

4. BIAN, Y. et al. Effusion cytology of desmoplastic small round cell tumor of the pleura. A case report. Acta Cytol, v. 37, n. 1, p. 77-82, 1993.

5. CHANG, F. Desmoplastic small round cell tumors: cytologic, histologic, and immunohistochemical features. Arch Pathol Lab Med, v. 130, n. 5, p. 728-32, 2006.

6. CHARLES, A. K.; MOORE, I. E.; BERRY, P. J. Immunohistochemical detection of the Wilms' tumour gene WT1 in desmoplastic small round cell tumour. Histopathology, v. 30, n. 4, p. 312-4, 1997.

7. CUMMINGS, O. W. et al. Desmoplastic small round cell tumors of the paratesticular region. A report of six cases. Am J Surg Pathol, v. 21, n. 2, p. 219-25, 1997.

8. DEVOE, K.; WEIDNER, N. Immunohistochemistry of small round-cell tumors. Semin Diagn Pathol, v. 17, n. 3, p. 216-24, 2000.

9. FLETCHER, J. A. Cytogenetics and experimental models of sarcomas. Curr Opin Oncol, v. 6, n. 4, p. 367-71, 1994.

10. GERALD, W. L. et al. Clinical, pathologic, and molecular spectrum of tumors associated with $\mathrm{t}(11 ; 22)(\mathrm{p} 13 ; \mathrm{q} 12)$ : desmoplastic small round-cell tumor and its variants. $J$ Clin Oncol, v. 16, n. 9, p. 3028-36, 1998.

11. GERALD, W. L. et al. Intra-abdominal desmoplastic small round cell-tumor. Report of 19 cases of a distinctive type of high-grade polyphenotypic malignancy affecting young individuals. Am J Surg Pathol, v. 15, n. 6, p. 499-513, 1991.

12. GERALD, W. L.; ROSAI, J. Case 2. Desmoplastic small cell tumor with divergent differentiation. Pediatr Pathol, v. 9, n. 2, p. 177-83, 1989.
13. GERALD, W. L.; ROSAI, J. Desmoplastic small cell tumor with multi-phenotypic differentiation. Zentralb/ Pathol, v. 139, n. 2, p. 141-51, 1993.

14. GIL, A. et al. Clinical perspective on desmoplastic small round-cell tumor. Oncology, v. 67, n. 3-4, p. 231-42, 2004.

15. HASSAN, I. et al. Intraabdominal desmoplastic small round cell tumors: a diagnostic and therapeutic challenge. Cancer, v. 104, n. 6, p. 1264-70, 2005.

16. KEMPSON, R. L. et al. Atlas of tumor pathology. Tumors of the soft tissue. Washington, DC: AFIP, 2001.

17. KRETSCHMAR, C. S. et al. Desmoplastic small cell tumor: a report of three cases and a review of the literature. J Pediatr Hematol Oncol, v. 18, n. 3, p. 293-8, 1996.

18. LAE, M. E. et al. Desmoplastic small round cell tumor: a clinicopathologic, immunohistochemical, and molecular study of 32 tumors. Am J Surg Pathol, v. 26, n. 7, p. 823-35, 2002.

19. LAL, D. R. et al. Results of multimodal treatment for desmoplastic small round cell tumors. J Pediatr Surg, v. 40 , n. 1, p. 251-5, 2005.

20. LEUSCHNER, I.; RADIG, K.; HARMS, D. Desmoplastic small round cell tumor. Semin Diagn Pathol, v. 13, n. 3, p. 204-12, 1996.

21. ORDÓÑEZ, N. G. etal. Intra-abdominal desmoplastic small cell tumor: a light microscopic, immunocytochemical, ultrastructural, and flow cytometric study. Hum Pathol, v. 24 , n. 8, p. 850-65, 1993 .

22. OUTWATER, E.; SCHIEBLER, M. L.; BROOKS, J. J. Intraabdominal desmoplastic small cell tumor: CT and MR findings. J Comput Assist Tomogr, v. 16, n. 3, p. 429-32, 1992.

23. QUAGLIA, M. P.; BRENNAN, M. F. The clinical approach to desmoplastic small round cell tumor. Surg Oncol, v. 9, n. 2, p. 77-81, 2000.

24. SAWYER, J. R.; TRYKA, A. F.; LEWIS, J. M. A novel reciprocal chromosome translocation $\mathrm{t}(11 ; 22)(\mathrm{p} 13 ; \mathrm{q} 12)$ in an intraabdominal desmoplastic small round-cell tumor. Am J Surg Pathol, v. 16, n.4, p. 411-6, 1992.

25. YOUNG, R. H. et al. Ovarian involvement by the intraabdominal desmoplastic small round cell tumor with divergent differentiation: a report of three cases. Hum Pathol, v. 23, n. 4, p. 454-64, 1992. 